\title{
Replication of the association between a chromosome 9p21 polymorphism and coronary artery disease in Japanese and Korean populations
}

\author{
Kunihiko Hinohara $\cdot$ Toshiaki Nakajima $\cdot$ Megumi Takahashi $\cdot$ Shigeru Hohda Taishi Sasaoka \\ Ken-ichi Nakahara $\cdot$ Kouji Chida $\cdot$ Motoji Sawabe $\cdot$ Takuro Arimura $\cdot$ Akinori Sato $\cdot$ \\ Bok-Soo Lee $\cdot$ Ji-min Ban $\cdot$ Michio Yasunami $\cdot$ Jeong-Euy Park $\cdot$ Toru Izumi $\cdot$ Akinori Kimura
}

Received: 20 December 2007/ Accepted: 26 December 2007/Published online: 9 February 2008

(C) The Japan Society of Human Genetics and Springer 2008

\begin{abstract}
Coronary artery disease (CAD) has become a major health problem in many countries. Recent genomewide association studies have identified the association between rs1333049 on chromosome 9p21 and susceptibility to CAD in Caucasoid populations. In this study, we evaluated the associations of rs 1333049 with CAD in Japanese (604 patients and 1,151 controls) and Koreans (679 patients and 706 controls). We found a significant association in both Japanese [odds ratio $(\mathrm{OR})=1.30,95 \%$
\end{abstract}

K. Hinohara $\cdot$ T. Nakajima $\cdot$ M. Yasunami $\cdot$ A. Kimura

Laboratory of Genome Diversity, School of Biomedical Science,

Tokyo Medical and Dental University, Tokyo, Japan

T. Nakajima $\cdot$ M. Takahashi $\cdot$ T. Arimura $\cdot$ A. Sato ·

M. Yasunami · A. Kimura $(\square)$

Department of Molecular Pathogenesis, Medical Research

Institute, Tokyo Medical and Dental University,

2-3-10 Kandasurugadai, Chiyoda-ku, Tokyo 101-0062, Japan

e-mail: akitis@mri.tmd.ac.jp

S. Hohda $\cdot$ T. Sasaoka $\cdot$ T. Izumi

Department of Cardiology,

Kitasato University School of Medicine, Sagamihara, Japan

K. Nakahara

Division of Internal Medicine, National Hospital Organization

Nagasaki Medical Center, Ohmura, Japan

K. Chida

Department of Cardiology, Tokyo Metropolitan

Geriatric Medical Center, Tokyo, Japan

M. Sawabe

Department of Pathology, Tokyo Metropolitan

Geriatric Medical Center, Tokyo, Japan

B.-S. Lee · J. Ban · J.-E. Park

Division of Cardiology, Samsung Medical Center,

Seoul, South Korea confidence interval (CI); $1.13-1.49, p=0.00027$, allele count model] and Koreans $(\mathrm{OR}=1.19,95 \% \mathrm{CI} ; 1.02$ $1.38, p=0.025$, allele count model). These observations demonstrated that chromosome 9p21 was the susceptibility locus for CAD also in East Asians.

Keywords Coronary artery disease .

9p21 - Single nucleotide polymorphism .

Case-control study $\cdot$ Japanese $\cdot$ Korean

\section{Introduction}

Coronary artery disease (CAD), clinically manifested with angina pectoris (AP) or myocardial infarction (MI), has become a major health problem in many countries because of its increasing prevalence and high mortality. Although non-genetic factors such as smoking, hypertension, hypercholesterolemia and diabetes mellitus significantly contribute to development of $\mathrm{CAD}$, considerable evidence indicates the involvement of genetic factors in the pathogenesis of CAD (Wang 2005). Recent large scale association studies have accumulated information on the susceptibility genes linked to CAD. Notably, genome-wide association studies repeatedly identified the association of the chromosome 9p21 locus with the susceptibility to CAD in Caucasoid populations (Wellcome Trust Case Control Consortium 2007; McPherson et al. 2007; Helgadottir et al. 2007; Samani et al. 2007). In general, one of the main problems in association studies is the lack of reproducibility, which indicates that contribution of the reported factor is not common or not large enough to be replicated in other studies (Morgan et al. 2007). Therefore, validation studies are indispensable to clarify the genes involved in the pathogenesis, though there might be ethnic differences 
in the genetic backgrounds or regional differences in the environmental or lifestyle factors even in the same ethnic groups. In this study, we evaluated the association of rs1333049with CAD in Japanese and Korean populations.

\section{Materials and methods}

\section{Subjects}

The study protocol was approved by the Ethics Review Boards of the Medical Research Institute of Tokyo Medical and Dental University, Kitasato University School of Medicine, Tokyo Metropolitan Geriatric Medical Center, and Samsung Medical Center. Japanese subjects consisted of 604 patients and 1,151 controls, while Korean subjects included 679 patients and 706 controls. The Japanese control group was comprised of healthy volunteers without a history of CAD $(n=633)$ and consecutive autopsied persons without pathological findings of acute or old MI $(n=518)$. Korean control subjects were randomly selected from healthy individuals $(n=182)$ and cancer patients $(n=524)$ without a history of CAD. The diagnosis of CAD and classical risk factors was based on the standard criteria as described previously (Hohda et al. 2003). Severity of coronary atherosclerosis was classified according to the number of coronary vessels with significant stenosis (angiographic luminal stenosis $>50 \%$ ) as one-, two-, or three-vessel disease (VD).

\section{Genotyping}

TaqMan SNP genotyping assay (Applied Biosystems) was used to determine the genotype of rs1333049 in PCR products generated with primer pair rs1333049-F (5'CCTTCATGCTATTTTGAGGAG) and rs1333049-R (5'GGAAGATAAGTTGAGAATGTCA).

\section{Statistical analysis}

Genotype distributions and allele frequencies were compared between the cases and controls using a chi-square test. When the $p$ value was less than 0.05 , the association was considered to be significant. Strength of the association was expressed by odds ratio (OR). Significance of the association with coronary disease severity was examined by Mann-Whitney $U$-test.

\section{Results and discussion}

Five SNPs on the chromosome 9p21 locus, rs1333049, rs10757274, rs2383206, rs2383207, and rs10757278, were associated with $\mathrm{CAD}$, and they were in tight $\mathrm{LD}$ in Caucasians. Because the structure of LD based on HapMap database information suggested that they were also in tight LD in Asians, we used rs1333049 in this study. As shown in Table 1, the genotype distribution was in HardyWeinberg equilibrium in all tested populations. There was significant association at the allele count model in both Japanese $(\mathrm{OR}=1.30,95 \% \mathrm{CI} ; 1.13-1.49, p=0.00027)$ and Korean $(\mathrm{OR}=1.19,95 \% \mathrm{CI} ; 1.02-1.38, p=0.025)$, confirming the association in East Asian populations. A replication study in Korean by using different SNPs was recently reported (Shen et al. 2008). These data strongly suggested that the chromosome 9p21 locus conferred susceptibility to CAD across racial lines.

Because previous studies did not address the correlation between the risk allele and phonotypic background of CAD, we investigated the association between rs1333049 and severity of atherosclerosis. According to the number of significantly affected vessels, CAD patients were classified into three groups, $1 \mathrm{VD}, 2 \mathrm{VD}$ and $3 \mathrm{VD}$. As shown in Table 2, there was no trend of association between the rs1333049 genotype and severity of CAD in both Japanese and Koreans (Table 2). Stratified analyses of rs1333049 with risk factors of CAD such as diabetes mellitus, hyperlipidemia, or hypertension showed again no trend of association between rs1333049 and risk factors (data not

Table 1 Association of rs1333049 on chromosome 9p21 with CAD in Japanese and Koreans

\begin{tabular}{lllll}
\hline Genotype & $\begin{array}{l}\text { CAD } \\
(n=604)\end{array}$ & $\begin{array}{l}\text { Control } \\
(n=1,151)\end{array}$ & OR (95\%CI) & $p$ value \\
& $n(\%)$ & $n(\%)$ & \\
\hline
\end{tabular}

\begin{tabular}{lllll}
\hline (a) Japanese & & & & \\
GG & $114(18.9)$ & $286(24.9)$ & $0.70(0.55-0.90)$ & 0.0046 \\
GC & $312(51.7)$ & $606(52.7)$ & $0.96(0.79-1.17)$ & $\mathrm{ns}$ \\
CC & $178(29.5)$ & $259(22.5)$ & $1.44(1.15-1.80)$ & 0.0013 \\
$\begin{array}{l}\text { C allele } \\
\text { frequency }\end{array}$ & 0.55 & 0.49 & $1.30(1.13-1.49)$ & 0.00027 \\
HWE $(p)$ & 0.54 & 0.19 & & \\
\hline Genotype & CAD & $\begin{array}{l}\text { Control } \\
(n=706)\end{array}$ & OR (95\%CI) & $p$ value \\
& $\begin{array}{l}n=679) \\
n(\%)\end{array}$ & & \\
\hline
\end{tabular}

\begin{tabular}{lllll}
\hline (b) Korean & & & & \\
GG & $158(23.3)$ & $192(27.2)$ & $0.81(0.64-1.04)$ & ns \\
GC & $335(49.3)$ & $353(50.0)$ & $0.97(0.79-1.20)$ & ns \\
CC & $186(27.4)$ & $161(22.8)$ & $1.28(1.00-1.63)$ & 0.049 \\
C allele & 0.52 & 0.48 & $1.19(1.02-1.38)$ & 0.025 \\
$\quad$ frequency & & & & \\
HWE $(p)$ & 0.96 & 1.00 & &
\end{tabular}

$C A D$ coronary artery disease, $O R$ odds ratio, $C I$ confidence interval, $H W E$ Hardy-Weinberg equilibrium, $n s$ not significant, $(p>0.05)$ 
Table 2 Association of rs1333049 on chromosome 9p21 with the severity of coronary atherosclerosis

\begin{tabular}{|c|c|c|c|c|}
\hline & \multicolumn{2}{|c|}{ Japanese CAD } & \multicolumn{2}{|c|}{ Korean CAD } \\
\hline & $\begin{array}{l}\mathrm{CC} \\
n(\%)\end{array}$ & $\begin{array}{l}\text { Non-CC } \\
n(\%)\end{array}$ & $\begin{array}{l}\mathrm{CC} \\
n(\%)\end{array}$ & $\begin{array}{l}\text { Non-CC } \\
n(\%)\end{array}$ \\
\hline 1VD & $77(31.4)$ & $168(68.6)$ & $64(27.5)$ & $169(72.5)$ \\
\hline 2VD & $54(31.0)$ & $120(69.0)$ & $41(25.0)$ & $123(75.0)$ \\
\hline $3 \mathrm{VD}$ & $46(25.6)$ & $134(74.4)$ & $31(27.4)$ & $82(72.6)$ \\
\hline Mann-Whitney $U$ & $p=0.22$ & & $p=0.86$ & \\
\hline
\end{tabular}

$C A D$ coronary artery disease, $V D$ vessel disease means significantly affected vessel (angiographic luminal stenosis $>50 \%$ ). Angiographic data were available for 599 Japanese patients and 510 Korean patients. Significance of the association with coronary disease severity was examined by Mann-Whitney $U$-test

shown). Though further studies are required to decipher the mechanism of involvement of this locus to the pathogenesis of CAD, the observations in this study strongly suggested that the chromosome 9p21 locus was a genetic risk factor independent of classical risk factors.

Acknowledgments This work was supported in part by a Grantin-Aid for Scientific Research from the Ministry of Education, Culture, Sports, Science and Technology of Japan and a grant for Japan-Korea collaboration research from Japan Society for the Promotion of Science and by KOSEF grant, the Korea-Japan Basic Scientific Cooperation Program (F01-2005-000-10275-0).

\section{References}

Helgadottir A, Thorleifsson G, Manolescu A, Gretarsdottir S, Blondal T, Jonasdottir A, Jonasdottir A, Sigurdsson A, Baker A, Palsson
A, Masson G, Gudbjartsson DF, Magnusson KP, Andersen K, Levey AI, Backman VM, Matthiasdottir S, Jonsdottir T, Palsson S, Einarsdottir H, Gunnarsdottir S, Gylfason A, Vaccarino V, Hooper WC, Reilly MP, Granger CB, Austin H, Rader DJ, Shah SH, Quyyumi AA, Gulcher JR, Thorgeirsson G, Thorsteinsdottir U, Kong A, Stefansson K (2007) A common variant on chromosome $9 \mathrm{p} 21$ affects the risk of myocardial infarction. Science 316:1491-1493

Hohda S, Kimura A, Sasaoka T, Hayashi T, Ueda K, Yasunami M, Okabe M, Fukuta N, Kurosawa T, Izumi T (2003) Association study of CD14 polymorphism with myocardial infarction in a Japanese populations. Jpn Heart J 44:613-622

McPherson R, Pertsemlidis A, Kavaslar N, Stewart A, Roberts R, Cox DR, Hinds DA, Pennacchio LA, Tybjaerg-Hansen A, Folsom AR, Boerwinkle E, Hobbs HH, Cohen JC (2007) A common allele on chromosome 9 associated with coronary heart disease. Science 316:1488-1491

Morgan TM, Krumholz HM, MD, Lifton RP, Spertus JA (2007) Nonvalidation of reported genetic risk factors for acute coronary syndrome in a large-scale replication study. JAMA 297:15511561

Samani NJ, Erdmann J, Hall AS, Hengstenberg C, Mangino M, Mayer B, Dixon RJ, Meitinger T, Braund P, Wichmann HE, Barrett JH, König IR, Stevens SE, Szymczak S, Tregouet DA, Iles MM, Pahlke F, Pollard H, Lieb W, Cambien F, Fischer M, Ouwehand W, Blankenberg S, Balmforth AJ, Baessler A, Ball SG, Strom TM, Braenne I, Gieger C, Deloukas P, Tobin MD, Ziegler A, Thompson JR, Schunkert H, WTCCC, the Cardiogenics Consortium (2007) Genomewide association analysis of coronary artery disease. N Engl J Med 357:443-453

Shen GQ, Li L, Rao S, Abdullah KG, Ban JM, Lee BS, Park JE, Wang QK (2008) Four SNPs on chromosome 9p21 in a South Korean Population implicate a genetic locus that confers high cross-race risk for development of coronary artery disease. Arterioscler Thromb Vasc Biol 28:360-365

Wang Q (2005) Molecular genetics of coronary artery disease. Curr Opin Cardiol 20:182-188

Wellcome Trust Case Control Consortium (2007) Genome-wide association study of 14,000 cases of seven common diseases and 3,000 shared controls. Nature 447:661-678 